\title{
Study of Chromium Effect on Structure and Wear-Resisting Properties of Complex Alloyed Brass
}

\author{
Maksim O. Ivkin ${ }^{1,2, *}$, Raisa K. Mysik ${ }^{3}$, Sergej V. Brusnicyn ${ }^{3}$, and Andrej V. Sulicin ${ }^{3}$ \\ ${ }^{1}$ UMMC, 1 Uspenskiy Ave., Verkhnaya Pyshma, Sverdlovsk Region, 624091, Russian Federation \\ 2 PJSC "RZ OCM", 1 Kombinatskaya Str., Revda, Sverdlovsk Region, 623280, Russian Federation \\ ${ }^{3}$ Ural Federal University, 19 Mira Str., Ekaterinburg, 620002, Russian Federation
}

\begin{abstract}
The microstructure of $\mathrm{CuZnMnAlSiNiCr}$ complex alloyed brass was examined. The effect of various chromium content in the range from 0.00 to $0.33 \mathrm{wt} . \%$ on the composition and morphology of intermetallic compounds was established, and the amount of chromium-based intermetallic compounds was estimated. Microhardness of intermetallic compounds of various morphology was determined. The effect of chromium content on wear rate of brass samples was estimated. The range of chromium content at which samples wear rate is minimal was estimated.
\end{abstract}

\section{Introduction}

Currently, the automotive industry increases at a rapid rate, resulting in increased demand for various special-purpose materials. Such materials include complex alloyed brass, which is widely used in the automotive industry [1-5]. Complex alloyed brass is a copper-zinc alloy additionally alloyed with $\mathrm{Al}, \mathrm{Si}, \mathrm{Mn}, \mathrm{Fe}, \mathrm{Ni}, \mathrm{Ti}, \mathrm{Pb}$, etc. A great number of alloying components provide the required mechanical properties and performance: hardness, plasticity, wear resistance, good thermal conductivity, corrosion resistance, strength, while the cost of complex alloyed brass is lower compared to other tribotechnical materials.

It should be noted that the required level of performance is ever-increasing with increasing requirements for reliability and service life of high-duty products. For this purpose, the effects of various alloying elements on brass properties have been researched [6,7]. Wear resistance is one of the main parameters that determines the durability of parts operating under heavy wear, significantly affects the level of harmful emissions in industry and mechanical engineering [8]. In complex alloyed brass, wear resistance depends upon the ratio of structural phases $[9,10]$, the amount and shape of intermetallic components (a number of alloying elements form intermetallic compounds that reinforce groundmass, thereby increasing wear resistance [11,12]). The effect of silicon and manganese on wearresisting properties complex alloyed brass has been widely studied [13]. Recently, there has been increasing interest in copper-based alloys additionally alloyed with chromium [14].

\footnotetext{
* Corresponding author: ivkinmaxim@gmail.com
} 
The purpose of this work is to study the effect of chromium content on the structure and wear rate of CuZnMnAlSiNiCr brass samples.

\section{Research material and methods}

To study the effect of chromium on the structure and properties of CuZnMnAlSiNiCr brass, 8 samples with a chromium content of 0.00 to $0.33 \%$ were melted in a laboratory resistance crucible furnace. First, a test charge of electrolytic copper and zinc was melted, then the melt was alloyed with pure manganese, aluminum, silicon and nickel.

The content of alloying elements in the alloy was as follows, wt. \%: $62 \mathrm{Cu}, 3 \mathrm{Mn}, 2 \mathrm{Al}$, $0.8 \mathrm{Si}, 0.4 \mathrm{Ni}$. Chromium was added as part of master alloy. Redox flux was used to reduce element losses and slagging. Samples $20 \mathrm{~mm}$ in diameter and $30 \mathrm{~mm}$ in height were cast into a graphite mold heated to $200{ }^{\circ} \mathrm{C}$. Metallographic analysis of alloy microstructure was carried out using an Altami Met-1M metallographic microscope. To assess the microstructure, the samples were etched in a 1:1 mixture of $\mathrm{CH}_{3} \mathrm{COOH}$ and $\mathrm{HNO}_{3}$. The amount of intermetallic compounds per unit area was estimated using SIAMS 700 program. Microhardness was measured using an HMV-G21DT Shimadzu microhardness tester. For tribological testing, $7 \times 7 \times 15 \mathrm{~mm}$ samples were made. Wearing test was carried out according to the pin and plate scheme using a laboratory tribological unit. The sample was moved backward and forward along a fixed C45 steel plate (according to EN 10277-2-2008) in the air at a temperature of $22^{\circ} \mathrm{C}$ and a normal load of $30 \mathrm{~kg}$. Sample stroke was $40 \mathrm{~mm}$ and 2,000 double strokes were performed. During the test, the friction force was continuously recorded using a ring (spring) with resistance strain gauge attached to the surface. The spring was calibrated with calibration weights. Special ZETView software and a PC were used to process strain gauge signals recorded using the ZET-210 ADC module with a ZET 412 preamplifier.

\section{Results and Discussions}

Analysis of the microstructure of obtained ingots showed that the shape and size of intermetallic compounds in the alloy change significantly with increasing amount of chromium added to the melt. Figure 1 shows the microstructure of a chromium-free alloy ingot.
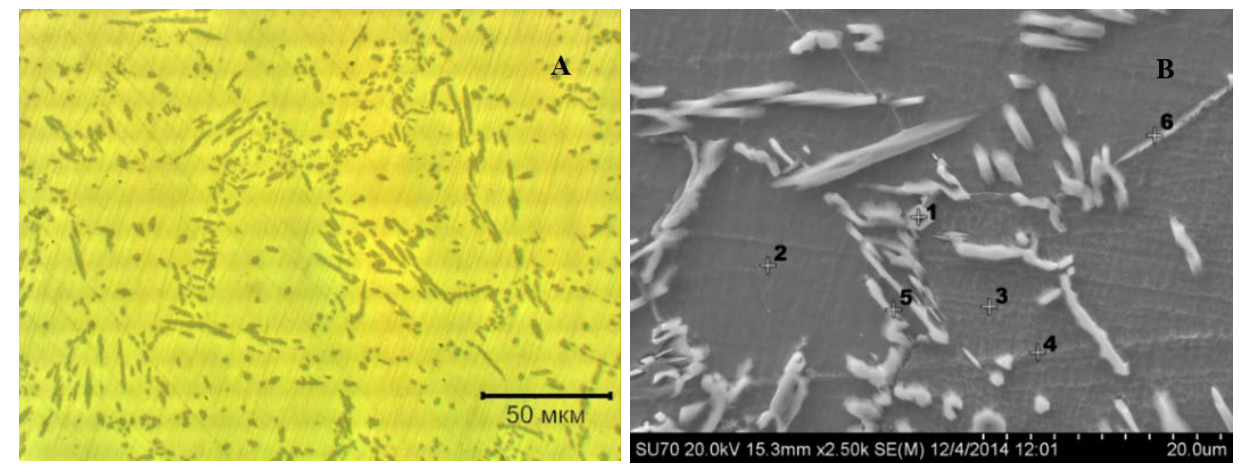

Fig. 1. Microstructure of chromium-free alloy ingot: (A) optical micrograph; (B) SEM micrograph.

Analysis of the microstructure and chemical composition of phases using a Hitachi SU70 scanning electron microscope with an NSS312E accessory showed that the alloy has an intermetallic phase consisting of manganese silicides $\mathrm{Mn}_{5} \mathrm{Si}_{3}$ containing $67.25 \% \mathrm{Mn}$ and $20.41 \% \mathrm{Si}$. Intermetallic compounds of this composition are oblong. Microhardness of 
oblong intermetallic compounds is $600 \ldots 900 \mathrm{HV}$. Intermetallic compounds are mainly located along grain boundaries. Groundmass is composed of copper and zinc.

Figure 2 shows the microstructure of an alloy ingot with $0.15 \%$ chromium content.
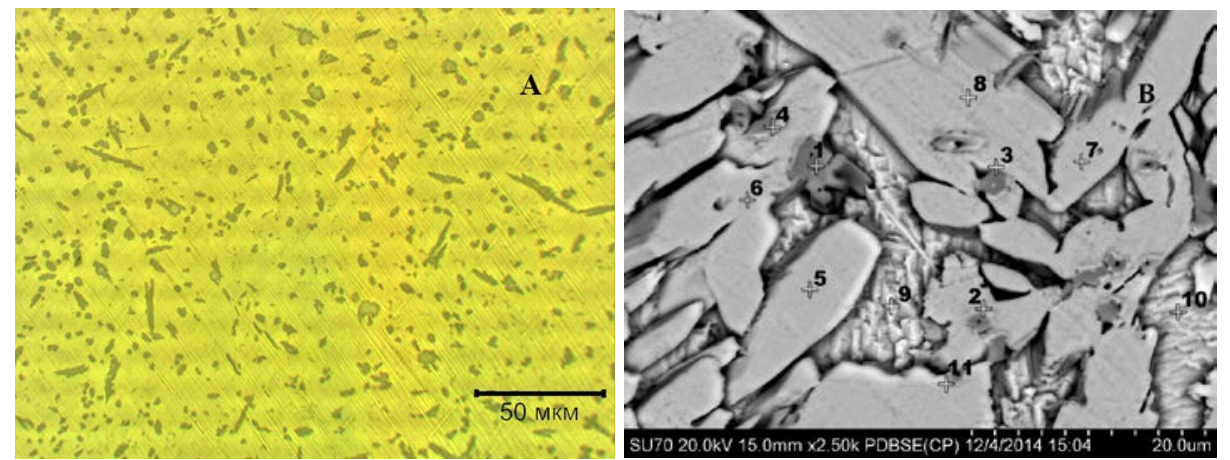

Fig. 2. Microstructure of alloy ingot with $0.15 \%$ chromium content: (A) optical micrograph; (B) SEM micrograph.

Analysis of phase microstructure and chemical composition showed that inclusions of intermetallic compounds are evenly distributed in the groundmass. In addition to oblong $\mathrm{Mn}_{5} \mathrm{Si}_{3}$ intermetallic compounds, alloy has rounded inclusions with a gray core (Figure 2). Analysis of the chemical composition of such an inclusion (point 1, Figure 2) showed that its core is a $\mathrm{Cr}_{3} \mathrm{Si}$ intermetallic compound containing $77.06 \% \mathrm{Cr}$ and $16.60 \% \mathrm{Si}$. The dark shell of such an inclusion consists of $\mathrm{Mn}_{5} \mathrm{Si}_{3}$ manganese silicide. Microhardness of the central part of a rounded inclusion is about $1,500 \mathrm{HV}$.

Figure 3 shows the microstructure of an alloy ingot with $0.33 \%$ chromium content.
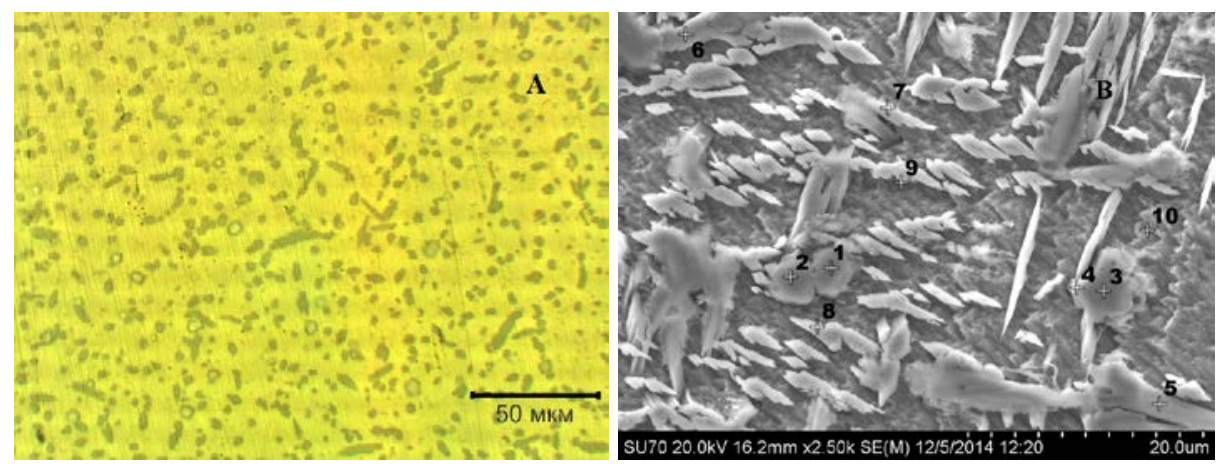

Fig. 3. Microstructure of alloy ingot with $0.33 \%$ chromium content: (A) optical micrograph; (B) SEM micrograph.

With $0.33 \%$ chromium content (Figure 3), the amount of rounded intermetallic compounds significantly increases. Moreover, there has been a decrease in the length of oblong intermetallic compounds from $30 \ldots 40 \mu \mathrm{m}$ in chromium-free alloy to $15 \mu \mathrm{m}$ in $0.33 \%$ chromium alloy with an increase in their width from $1 \ldots 1.5 \mu \mathrm{m}$ to $3.5 \mu \mathrm{m}$, respectively. To quantitatively analyze the alloy structure, the amount of rounded intermetallic compounds in $1 \mathrm{~mm}^{3}$ of the alloy was calculated using the following formula (1) [15]:

$$
N_{v}=\frac{n_{s}}{D_{\text {avg }}}
$$

where $n_{s}$ is the number of rounded intermetallic compounds per $1 \mathrm{~mm}^{2} ; \mathrm{D}_{\mathrm{avg}}$ is the average size of intermetallic compounds. 
Wear rate was calculated using the following formula (2):

$$
I_{h}=\frac{Q}{\rho \cdot S \cdot L}
$$

where $\mathrm{Q}$ is sample weight loss, $\mathrm{g}$; $\rho$ is density of sample material, $\mathrm{g} / \mathrm{cm}^{3} ; \mathrm{S}$ is geometric contact area, $\mathrm{cm}^{2}$; $\mathrm{L}$ is the friction distance, $\mathrm{cm}$.

Table 1 presents the estimation of rounded intermetallic compounds and wear rate of all samples.

Table 1. Quantitative assessment of complex alloyed brass microstructure and sample wear rate depending on chromium content.

\begin{tabular}{|c|c|c|}
\hline $\begin{array}{c}\text { Chromium content, } \\
\text { wt. \% }\end{array}$ & $\begin{array}{c}\text { Number of rounded } \\
\text { intermetallic } \\
\text { compounds per } \\
1 \mathrm{~mm}^{2} \text {, pcs. }\end{array}$ & Wear rate \\
\hline 0.00 & 0 & 7.3 \\
\hline 0.05 & 3,000 & 7.1 \\
\hline 0.14 & 20,000 & 6.8 \\
\hline 0.15 & 39,000 & 6.6 \\
\hline 0.16 & 43,000 & 5.7 \\
\hline 0.17 & 50,000 & 5.5 \\
\hline 0.23 & 138,000 & 4.2 \\
\hline 0.33 & 346,000 & 6.1 \\
\hline
\end{tabular}

Table 1 shows that increased chromium content in the alloy increases the number of rounded intermetallic compounds in its structure and reduces sample wear rate. This tendency is explained by the Charpy-Bochvar principle. According to this principle, the hardest constituents of alloy should be evenly distributed in the softer and more ductile groundmass, and solids should be isolated from each other. According to the Orowan mechanism, when the groundmass has uniformly distributed solids, dislocation motion is hindered. Therefore, friction-induced areal deformation wear is reduced [16]. However, at a chromium content of $0.33 \%$, as the number of rounded intermetallic compounds increases, wear rate also increases. With a significant increase in the number of rounded intermetallic compounds per unit volume of alloy, dispersed phase (intermetallic compounds) aggregates. Previous studies [17] showed that with a 5\% volume ratio of the dispersed phase, particles are highly likely to aggregate. $5 \%$ volume percentage of intermetallic compounds corresponds to an alloy sample with $0.33 \%$ chromium content. Aggregation of intermetallic compounds results in micropores [18], which affects performance.

\section{Conclusions}

The studies have shown that as chromium content in CuZnMnAlSiNiCr complex alloyed brass increases, the morphology of intermetallic compounds in the alloy changes. Chromiumfree alloys have only oblong intermetallic compounds; when chromium is added into the alloy, round intermetallic compounds are formed.

It has been found that $\mathrm{Mn}_{5} \mathrm{Si}_{3}$ intermetallic compounds are less hard than $\mathrm{Cr}_{3} \mathrm{Si}$ intermetallic compounds.

Increasing chromium content in the alloy results in lower wear rate; however, when the chromium content in the alloy is above $0.23 \%$, wear rate increases. 


\section{References}

1. Y. Chen, Automotive Transmissions (Springer Singapore, Singapore, 2021).

2. N. B. Pugacheva, Y. V. Khudorozhkova, E. B. Trushina, A. V. Gerasimova, and N. P. Antenorova, Reasons for Cracking of Die-Forged CuZn34Mn3Al2FeNi Brass Blanks, Diagnostics, Resour. Mech. Mater. Struct. 4, 61 (2017).

3. N. B. Pugacheva, A. V. Lebed, and A. S. Ovchinnikov, Ways to Improve LMtsAZHN Complex Alloyed Brass Tubes Manufacturing, in Innovation in Materials Science and Metallurgy. 2nd International Interactive Research-to-Practice Conference Proceeding, Ekaterinburg (2012), pp. 209-211.

4. M. V. Myasnikova, S. V. Smirnov, and N. B. Pugacheva, Simulation of Silicide Damage in Brass under Plastic Deformation, Fundam. Res. 9, 667 (2012).

5. M. Kondracki, J. Gawro'nski, and J. Szajnar, Role of the Intermetallic Phases in Technological Process of Fixture Brasses, J. Mater. Process. Technol. 162-163, 332 (2005).

6. W. Chen, Y. Jia, J. Yi, M. Wang, B. Derby, and Q. Lei, Effect of Addition of Ni and Si on the Microstructure and Mechanical Properties of $\mathrm{Cu}-\mathrm{Zn}$ Alloys, J. Mater. Res. 32, 3137 (2017).

7. S. Chen, X. Mi, G. Huang, and Y. Li, Effect of Ce Addition on Microstructure and Properties of Cu-Zn-Mn-Al-Based Alloy, J. Mater. Res. 32, 3137 (2017).

8. S. W. Zhang, Recent Developments of Green Tribology, Surf. Topogr. Metrol. Prop. 4, 023004 (2016).

9. H. Mindivan, H. Cimenoglu, and S. E. Kayali, Microstructures and Wear Properties of Brass Synchroniser Rings, Wear 254, 532 (2003).

10. A. Waheed and N. Ridley, Microstructure and Wear of Some High-Tensile Brasses, J. Mater. Sci. 29, 1692 (1994).

11. X. Wang, J. Jie, S. Liu, Z. Dong, G. Yin, and T. Li, Growth Mechanism of Primary Ti5Si3 Phases in Special Brasses and Their Effect on Wear Resistance, J. Mater. Sci. Technol. 61, 138 (2021).

12. H. Li, J. Jie, Q. Zhang, and T. Li, Effect of Annealing Treatment on the Microstructures, Mechanical, and Wear Properties of a Manganese Brass Alloy, J. Mater. Res. 31, 1491 (2016).

13. H. Li, J. Jie, S. Liu, Y. Zhang, and T. Li, Crystal Growth and Morphology Evolution of D8 8 (Mn, Fe) 5 Si 3 Phase and Its Influence on the Mechanical and Wear Properties of Brasses, Mater. Sci. Eng. A 704, 45 (2017).

14. M. Zare and M. Ketabchi, Effect of Chromium Element on Transformation, Mechanical and Corrosion Behavior of Thermomechanically Induced Cu-Al-Ni Shape-Memory Alloys, J. Therm. Anal. Calorim. 127, 2113 (2017).

15. S. A. Saltykov, Stereometric Metallography (Stereology of Metallic Materials) (Moscow: Metallurgy, 1976).

16. L. Bie, X. Chen, P. Liu, T. Zhang, and X. Xu, Morphology Evolution of Mn5Si3 Phase and Effect of Mn Content on Wear Resistance of Special Brass, Met. Mater. Int. 26, 431 (2020).

17. Y. P. Kozyrev and E. B. Sedakova, The Effect of the Process of Directed Aggregation of Particles on the Characteristics of Polymer Antifriction Nanocomposites, J. Mach. Manuf. Reliab. 39, 375 (2010).

18. N. B. Pugacheva, Structure of Industrial $\alpha+\beta$-Brass, Met. Sci. Heat Treat. Met. 23 (2007). 